\title{
Efeito do manejo pré-abate sobre alguns parâmetros fisiológicos em fêmeas suínas pesadas
}

\author{
Effect of pre-slaughter management on physiological parameters of heavy-weight female pigs
}

\author{
Osmar Antonio Dalla Costa ${ }^{\mathrm{I}}$ Jorge Vitor Ludke ${ }^{\mathrm{I}}$ Arlei Coldebella' ${ }^{\mathrm{I}}$ Jalusa Deon Kich ${ }^{\mathrm{I}}$ \\ Mateus José Rodrigues Paranhos da Costa ${ }^{\text {I1 }}$ Luigi Faucitano $^{\text {III }}$ José Vicente Peloso $^{\text {IV }}$ \\ Darlan Dalla Roza ${ }^{\mathrm{v}}$
}

\section{RESUMO}

O objetivo neste trabalho foi avaliar o efeito do período de descanso (3, 5, 7 e 9 horas) dos suínos no frigorífico (PDF) e da localização dos suínos na carroceria do caminhão $(P B O)$, quando transportados, no inverno ou verão, sobre alguns parâmetros fisiológicos avaliados em 64 fêmeas, com peso médio de $130 \mathrm{~kg}$ para abate, durante o manejo pré-abate. Para a análise estatística, foram considerados, no modelo de análise da variância, os efeitos de bloco, PDF, PBO e da interação (bloco x PDF), entre outros. O PDF influenciou, significativamente, as concentrações de lactato no sangue $e$ cortisol na saliva. Suínos que descansaram 5 e 7 horas apresentaram maior concentração de lactato em relação aos animais que descansaram 3 e 9 horas. No transporte, a freqüência cardíaca foi muito maior em relação aos demais locais avaliados. Concluiu-se que o incremento do PDF não promove mudanças na freqüência cardíaca, nas concentrações de glicose e CPK no sangue e cortisol na saliva, mas interfere na concentração de lactato no sangue dos suínos.

Palavras-chave: bem-estar, cortisol, creatina fosfo-quinase, freqüência cardíaca, glicose, lactato.

\section{ABSTRACT}

The aim of the research was to evaluate the effect of pig lairage time (PDF=3, 5, 7 and 9 hours) and evaluate the effect of pig position into the truck $(\mathrm{PBO})$ during transportation to slaughterhouse, in winter or summer conditions, on some physiologic parameters evaluated on 64 heavyweight females with mean liveweight of $130 \mathrm{~kg}$ during pre-slaughter events. The following effects were considered in the statistical analysis of variance model: block ( $B L=$ summer farm or winter farm), $P D F, P B O$ and interaction (Block $\times P D F$ ), under other factors. The PDF influenced significativelly blood lactate and saliva cortisol levels. Pig submitted to 5 and 7 hours of lairage had higher levels of lactate when compared to pigs submitted to 3 and 9 hours of lairage. During transport the heart rate were higher than in other pre-slaughter events. It is concluded that increasing PDF above 3 hours had no effects on heart frequency, glucose and CPK levels and salivary cortisol levels but affects the blood lactate levels.

Key words: cortisol, creatine phosphokinase, heart frequency, glycose, lactate, welfare.

\section{INTRODUÇÃO}

O manejo pré-abate é um processo complexo que inclui uma série de operações seqüenciais, envolvendo o preparo dos animais na granja, o manejo dos animais durante o transporte e as condições de abate (jejum na granja, embarque, transporte, desembarque, alojamento nas baias do frigorífico, período de descanso, atordoamento e abate). Essas operações causam estresse e comprometem o bemestar animal, resultando potencialmente em perdas quantitativas e qualitativas na produção de carne suína. Muitos são os agentes estressores envolvidos no manejo pré-abate, ocasionando alterações

IPesquisador da Embrapa Suínos e Aves, CP 21, 89700-000, Concórdia, SC, Brasil. E-mail: osmar@cnpsa.embrapa.br

IIDepartamento de Zootecnia, Grupo de Estudos e Pesquisas em Etologia e Ecologia Animal (ETCO), Faculdade de Ciências Agrárias e Veterinárias (FCAV), Universidade Estadual Paulista (UNESP), Jaboticabal, SP, Brasil.

IIIAgriculture and Agri-Food Canada, Dairy and Swine Research and Development Centre, Lennoxville, Quebec, Canada.

${ }^{\text {Iv }}$ Sadia S.A., Concórdia, SC, Brasil.

vTRIEL-HT Indústria de Equipamentos Rodoviários Ltda, Erechim, RS, Brasil. 
metabólicas geradas como reação ao desconforto físico e emocional. O bem-estar dos suínos nesta fase da produção pode ser acessado, usando-se um conjunto de medidas comportamentais, fisiológicas, bioquímicas, patológicas e parâmetros relacionados à qualidade das carcaças e da carne.

Inúmeras pesquisas (BERTOLONI \& SILVEIRA, 2003; PÉREZ et al., 2002a; LUDTKE, 2004) têm indicado que o manejo pré-abate é estressante para os animais e influencia, negativamente, o seu bem-estar, interferindo nos níveis de cortisol, lactato, creatinafosfo-quinase (CPK) e na freqüência cardíaca.

Níveis normais de lactato, no soro sangüíneo de suínos para abate, submetidos a reduzido estresse pré-abate foram avaliados por HAMBRECHT et al. (2005) quantificando valores entre 11,9 e 15,6mmol $\mathrm{L}^{-1}$ porém, sob condições de estresse, esses valores duplicaram. LEBRET et al. (2006) determinaram valores de lactato que oscilavam entre 6,66 e $6,35 \mathrm{mmol} \mathrm{L}^{-1}$, para suínos criados ao ar livre e em sistema convencional, respectivamente.

As condições das carrocerias em que os suínos destinados ao abate são transportados afetam o bem-estar e a qualidade da carne. BARTON-GADE et al. (1996) relataram um efeito significativo do compartimento do transporte, especialmente, nos suínos transportados na parte dianteira e na parte traseira sobre a qualidade da carne e sobre as lesões da pele. Os efeitos, na qualidade da carne, eram possivelmente causados pelo estresse físico, originado pela necessidade de o animal manter a posição ereta, a fim contornar os efeitos adversos das vibrações que foram mais elevadas nessas posições (BARTON-GADE et al., 1996; RANDALL et al., 1996).

Adicionalmente, a duração do período de descanso dos suínos no frigorífico também é um potente fator de influência sobre a qualidade da carne e no bem-estar dos animais. Ao desembarcarem, quando da chegada ao frigorífico, os animais estão cansados e estressados devido ao manejo prévio a que foram submetidos. Do ponto de vista metabólico, torna-se necessário a metabolização hepática do excesso de ácido lático acumulado nos músculos e restabelecimento do equilíbrio homeostático sanguíneo que, somente pode ser alcançado, com a adoção de períodos de descanso adequados. O tempo ótimo de descanso parece ser, aproximadamente, de 2 a 3 horas (WARRISS et al., 1998; VAN DER WAL et al., 1999). Esse tempo, ótimo de descanso no frigorífico, porém irá depender, principalmente, das condições do manejo pré-abate, considerando-se todas as etapas de forma conjunta (jejum na granja, transporte, mistura de lotes, temperatura ambiente, tamanho dos lotes) e da intensidade dos estresses a que esses animais foram submetidos.

Assim, os objetivos neste trabalho foram avaliar a influência do manejo pré-abate de fêmeas suínas pesadas, no inverno e no verão, sobre o nível de cortisol na saliva e freqüência cardíaca e, simultaneamente, ainda avaliar o efeito do período de descanso dos suínos no frigorífico sobre os parâmetros sangüíneos (lactato, creatina-fosfo-quinase e glicose), quando os animais são transportados durante curto período de tempo e a curtas distâncias.

\section{MATERIAL E MÉTODOS}

No experimento, foram utilizadas 64 fêmeas oriundas de duas granjas em sistema de terminação de suínos, sendo 32 animais no verão (fevereiro de 2002, com temperatura mínima e máxima absoluta de $13,0^{\circ} \mathrm{C}$ e $33,5^{\circ} \mathrm{C}$, respectivamente) e 32 animais no inverno (julho de 2002, com temperatura mínima e máxima absoluta de $0,0^{\circ} \mathrm{C}$ e $29,0^{\circ} \mathrm{C}$, respectivamente). Os animais utilizados no presente estudo eram de oriundos de cruzamentos industriais, prole de fêmeas (Landrace x Large White), acasaladas com macho sintético-terminador, e apresentavam peso médio de $128,3 \pm 3,7 \mathrm{~kg}$ no inverno e $131,7 \pm 4,5 \mathrm{~kg}$ no verão, com um período de alojamento médio de 144 dias, para concluir as fases de crescimento e terminação. Nas granjas avaliadas, foram escolhidas, aleatoriamente, quatro baias (repetições) por período de descanso no frigorífico. Dos dez animais em cada baia foram escolhidos e identificados os dois mais uniformes (pesos semelhantes). No total, foram utilizadas 16 baias por granja para a realização do experimento. Para os períodos de descanso avaliados a unidade experimental considerada foi constituída por dois animais dentro da baia.

$\mathrm{Na}$ granja, os animais estavam alojados em baias coletivas com piso de concreto, com paredes de alvenaria rebocada, bebedouro do tipo concha (ecológico) e comedouro linear, paralelo ao corredor. Esses animais, na granja, foram submetidos a um jejum de sólidos durante 12 horas antes do embarque. $\mathrm{O}$ tempo gasto para o embarque foi de 54 e 49 minutos no inverno no verão, respectivamente. A granja utilizada no experimento realizado no inverno estava localizada a $39 \mathrm{~km}$ do frigorífico (distância percorrida em 54 minutos), enquanto que a granja utilizada para a realização do experimento no verão estava localizada a $27 \mathrm{~km}$ do frigorífico (distância percorrida em 40 minutos). O desembarque dos suínos, no frigorífico, foi realizado com o auxilio de rampa móvel. Os animais foram alojados em grupos e receberam períodos de descansos no frigorífico 
de 3, 5, 7 e 9 horas. Durante o deslocamento dos animais (embarque e desembarque), não foi utilizado choque elétrico, sendo a condução auxiliada com uma tábua de manejo.

O transporte foi realizado em um modelo de carroceria metálica dupla Triel-HT, com área total de $43,2 \mathrm{~m}^{2}$, que possuía capacidade para transportar 96 suínos, com uma densidade de $0,45 \mathrm{~m}^{2}$ por suíno. Os animais em avaliação, previamente distribuídos aos tratamentos de tempo de descanso no frigorífico, foram colocados nas posições dentro da carroceria de forma a conter um número idêntico de suínos de cada tratamento em cada posição avaliada. Nesse modelo de carroceria, foram considerados os efeitos de piso (inferior e superior), do lado (direito e esquerdo) e posição (frente, meio e atrás). Após os períodos de descanso avaliados, os suínos foram retirados das baias e atordoados, conforme descrito por DALLA COSTA et al. (2007). No abate (sangria) dos animais, foram coletadas amostras de sangue (8 suínos/ tratamento correspondendo aos tempos de descanso no abatedouro de 3, 5, 7 e 9 horas). Foram analisadas as enzimas Creatina-Fosfo-Quinase (CPK - método enzimático - Kit Wiener CK-NAC, Laboratório Wiener), a Lactato Dehidrogenase (pelo método enzimático Kit Rolsgreiner) e a glicose pelo método enzimático (Kit Ebram-70-05-Laboratório Ebram).

O monitoramento dos batimentos cardíacos foi realizado, simultaneamente, em 8 animais/tratamento por meio da utilização do sistema Polar Team System ${ }^{\mathrm{TM}}$. Esse aparelho foi colocado ao redor do tórax, no lado esquerdo do suíno e, sobre este, foi fixada uma faixa elástica com o objetivo de proteger e colar o equipamento no corpo do animal. Esses receptores possuem um sistema de memória para a coleta do número de batimentos cardíacos por unidade de tempo, em intervalos de 5 segundos. A freqüência cardíaca dos suínos foi avaliada num período de 24 horas antes do manejo pré-abate (FC_GR), envolvendo o período de jejum na granja, o dia do manejo do abate dos suínos, antes do embarque (FC_EM), no transporte (FC_TR) e durante o período de descanso dos suínos no frigorífico (FC_AB). Em função do grande número dos registros referentes à freqüência cardíaca, foi calculada a média das freqüências por suíno, dentro dos locais avaliados.

A saliva, para análise do cortisol, foi coletada em oito animais/tratamento com o auxílio de um swab gigante, colocando-o na boca do suíno, deixando-o mastigar até que o algodão estivesse umedecido com saliva. Posteriormente, a saliva foi extraída do algodão e coletada em tubo Eppendorf, o qual foi armazenado em congelador à temperatura de $-20^{\circ} \mathrm{C}$. A concentração de cortisol na saliva foi determinada através do kit Elisa Salimetrics, nos suínos avaliados na granja, um dia antes do abate, em cinco horários $(0,3,6,9,12$ horas), quando foi obtida a média desse período (CC_GR). O início da coleta na granja, no dia anterior ao embarque, foi estabelecido com base na hora programada para o início do carregamento dos animais no dia seguinte. No dia do abate, após o embarque dentro da carroceria (CC_EM), depois do desembarque na baia de descanso (CC_DE) e uma hora antes de abate os animais ( $\left.\mathrm{CC}_{-} \mathrm{AB}\right)$, também foram coletadas amostras de saliva.

Os dados referentes à concentração do cortisol, da glicose (CG) e lactato (CL) foram transformados para o logaritmo natural ( $\mathrm{Ln})$ e, posteriormente, assim como os dados da creatinafosfoquinase (CPK) sangüínea, foram analisados em procedimento GLM (SAS, 2001), mediante emprego do modelo (1): $\mathrm{Y}_{\mathrm{ijklmn}}=\mu+\mathrm{BL}_{\mathrm{i}}+\mathrm{PDF}_{\mathrm{j}}+(\mathrm{BL} \times \mathrm{PDF})_{\mathrm{ij}}+\mathrm{PBO}_{\mathrm{k}}$ $+\mathrm{PPI}_{1}+\mathrm{PLA}_{\mathrm{m}}^{\mathrm{ijk} k \mathrm{mn}}+\mathrm{e}_{\mathrm{ijklmn}}$ (1) sendo: $\mathrm{Y}_{\mathrm{ijklmn}}=$ concentração de glicose $(C G)$, lactato $(C L)$ e creatina-fosfoquinase (CPK) no sangue dos suínos; $\mu=$ média geral; $\mathrm{BL}_{\mathrm{i}}=$ bloco (estação do ano, $\mathrm{i}=1$ inverno e 2 verão); $\mathrm{PDF}_{\mathrm{j}}=$ período de descanso dos suínos no frigorífico antes do abate $\mathrm{j}=1$, 2, 3, 4 ( respectivamente, 3, 5, 7 e 9 horas de descanso); $\mathrm{PBO}_{\mathrm{k}}=$ posição do animal na carroceria, $\mathrm{k}=1$ (frente), 2 (meio) e 3 (atrás); $\mathrm{PPI}_{1}=$ piso da carroceria, $1=1$ (inferior) e 2 (superior); $\mathrm{PLA}_{\mathrm{m}}=$ lado da carroceria, $\mathrm{m}=1$ (direito) e 2 (esquerdo); $(\mathrm{BL} \times \mathrm{PDF})_{\mathrm{ij}}=$ interação entre bloco e período de descanso dos suínos, no frigorífico, antes do abate; $\mathrm{e}_{\mathrm{ijklmn}}=$ erro aleatório associado a cada observação.

Para análise estatística do cortisol, foi considerada a média das cinco avaliações realizadas na granja, representando o valor daquele período, e utilizando o modelo estatístico 2: $\mathrm{Y}_{\mathrm{ijkl}}=\mu+\mathrm{BL}_{\mathrm{i}}+\mathrm{PDF}_{\mathrm{j}}$ $+\left(\mathrm{BL}_{\mathrm{i}} \times \mathrm{PDF}_{\mathrm{j}}\right)+\varepsilon_{\mathrm{ijk}}+\mathrm{LO}_{1}+\left(\mathrm{LO}_{\mathrm{l}} \times \mathrm{BL}_{\mathrm{i}}\right)+\left(\mathrm{LO}_{1} \times \mathrm{PDF}_{\mathrm{j}}\right)+$ $\left(\mathrm{LO}_{1} \times \mathrm{BL}_{\mathrm{i}} \times \mathrm{PDF}_{\mathrm{j}}\right)+\mathrm{e}_{\mathrm{ijkl}}(2)$, sendo: $\mathrm{Y}_{\mathrm{ijkl}}=$ concentração de cortisol na saliva e freqüência cardíaca dos suínos; $\mu=$ média geral; $\mathrm{BL}_{\mathrm{i}}=$ bloco (estação do ano, $\mathrm{i}=1$ inverno) e 2 verão); $\mathrm{PDF}_{\mathrm{j}}=$ período de descanso dos suínos no frigorífico, $\mathrm{j}=1,2,3,4$ (descanso de $3,5,7$, 9 horas respectivamente); $(\mathrm{BL} \times \mathrm{PDF})_{\mathrm{ij}}=$ interação entre bloco e período de descanso dos suínos no frigorífico; $\varepsilon_{\mathrm{ijk}}=$ erro aleatório correspondente à parcela, suposto homocedástico, independente e normalmente distribuído; $\mathrm{LO}_{1}=$ local da coleta da saliva dos suínos, $1=1$ (na granja, 24 horas antes do embarque CC_GR); 2 (após o embarque dos suínos no caminhão CC_EM); 3 (após a desembarque dos suínos no frigorífico $\overline{C C} \_$DE); 4 (antes do abate dos suínos, na baia de descanso no frigorífico, CC_AB); $(\mathrm{LO} \times \mathrm{BL})_{\mathrm{li}}=$ interação entre local da coleta da saliva dos suínos e bloco; $(\mathrm{LO} \times \mathrm{PDF})_{\mathrm{lj}}=$ 
interação entre local da coleta da saliva dos suínos e período de descanso dos suínos no frigorífico; $(\mathrm{LO} \times \mathrm{BL} \times \mathrm{PDF})_{\mathrm{lij}}=$ interação entre local da coleta da saliva dos suínos e bloco e o período de descanso dos suínos no frigorífico; $\mathrm{e}_{\mathrm{ijk}}=$ erro aleatório correspondente à subparcela, suposto homocedástico, independente e normalmente distribuído.

\section{RESULTADOS E DISCUSSÃO}

O período de descanso no frigorífico não influenciou a concentração de glicose $(p=0,1048)$ e da CPK $(\mathrm{P}=0,2330)$ no sangue dos suínos, de acordo com a tabela 1. Os resultados obtidos, no presente estudo, diferem dos obtidos por PÉREZ et al. (2002a), que verificaram redução na concentração da glicose com o incremento do PDF e, dos obtidos por WARRISS et al. (1992; 1998), PÉREZ et al. (2002a) e GEESINK et al. (2004) que observaram esse mesmo comportamento para a CPK.

Verificou-se efeito $(\mathrm{P}=0,0419)$ do PDF sobre a concentração do lactato. Os valores de lactato, determinados no presente experimento, situam-se como intermediários aos determinados por LEBRET et al. (2006) e HAMBRECHT et al. 2005. Os suínos que descansaram por 3 horas apresentaram menor concentração de lactato no sangue, porém não diferiram significativamente $(\mathrm{P}>0,05)$, dos suínos que foram submetidos a um período de descanso de 9 horas. Os suínos que descansaram por 5 e 7 horas apresentaram valores de concentração de lactato intermediários e semelhantes entre si. Resultados de pesquisa (WARRISS et al., 1992) indicaram que, mesmo sob condições muito adversas de manejo, o nível de lactato retorna aos níveis normais após duas horas de descanso dos suínos de abate. Assim, os valores obtidos com o tempo de descanso de 3 horas corresponderam ao efeito físiológico de descanso imediato dos animais ao serem alojados nas baias no frigorífico. Entretanto, os valores de lactato obtidos com o tempo de 5 e 7 horas de descanso podem também corresponder ao efeito da mistura de animais da mesma granja de origem (porém de baias distintas) no frigorífico ou até corresponder a efeitos da temperatura ambiental, visto que os abates, nesse caso, ocorreram perto do meio dia. Nesse caso, o nível mais baixo, verificado 9 horas após a instalação dos animais nas baias de descanso, pode ser reflexo do período pósadaptação dos novos grupos formados nas baias e também corresponde ao primeiro abate realizado após o intervalo de almoço no frigorífico, onde o nível de atividade dos animais nas baias de descanso, cessa quase que completamente.

Esses resultados diferiram dos obtidos por PÉREZ et al. (2002b) GEESINK et al. (2004) e HAMBRECHT et al. (2005) que não encontraram efeito do período de descanso dos suínos no frigorífico sobre a concentração de lactato.

A localização do box, dentro da carroceria (frente, meio e atrás), não influenciou as concentrações

Tabela 1 - Médias ajustadas e desvios-padrão da concentração de glicose $\left(\mathrm{mg} \mathrm{dL}^{-1}\right)$, creatina-fosfo-quinase $-\mathrm{CPK}\left(\mathrm{U} \mathrm{L}^{-1}\right) \mathrm{e}$ lactato $\left(\mathrm{mg} \mathrm{dL}^{-1}\right)$ no sangue dos suínos em função do período de descanso no frigorífico e posição dos suínos dentro da carroceria do caminhão.

\begin{tabular}{lccc}
\hline Fatores de variação & Glicose & CPK & Lactato \\
\hline Período de descanso no frigorífico & & & \\
Descanso 3 horas & $93,50 \pm 14,85$ & $3028,87 \pm 2287$ & $65,86 \pm 23,01^{\mathrm{b}}$ \\
Descanso 5 horas & $96,18 \pm 6,62$ & $3344,94 \pm 3842$ & $83,73 \pm 25,57^{\mathrm{a}}$ \\
Descanso 7 horas & $100,42 \pm 8,08$ & $1965,25 \pm 1587$ & $84,96 \pm 15,87^{\mathrm{a}}$ \\
Descanso 9 horas & $97,17 \pm 7,02$ & $2676,69 \pm 1430$ & $75,24 \pm 18,19^{\mathrm{ab}}$ \\
Box & & & \\
Frente & $97,19 \pm 9,96$ & $1906,56 \pm 1491^{\mathrm{b}}$ & $78,02 \pm 23,64$ \\
Meio & $97,19 \pm 10,47$ & $3372,69 \pm 3027^{\mathrm{a}}$ & $74,70 \pm 24,62$ \\
Atrás & $98,38 \pm 8,17$ & $2982,56 \pm 2462^{\mathrm{a}}$ & $79,53 \pm 17,76$ \\
Piso & & & \\
Inferior & $95,71 \pm 7,25$ & $3034,41 \pm 2907$ & $76,21 \pm 18,99$ \\
Superior & $97,93 \pm 11,40$ & $2473,47 \pm 1890$ & $78,68 \pm 26,20$ \\
Lado & & & $76,77 \pm 23,13$ \\
Direito & $97,21 \pm 10,30$ & $3259,88 \pm 3065$ & $78,13 \pm 22,39$ \\
Esquerdo & $96,43 \pm 9,22$ & $2248,00 \pm 1523$ & \\
\hline
\end{tabular}

$\mathrm{Na}$ coluna, para cada grupo de fatores de variação, as médias seguidas de letras minúsculas distintas, diferem significativamente pelo teste $\mathrm{t}$ $(\mathrm{P}<0,05)$. 
de glicose $(\mathrm{P}=0,3104)$ e de lactato $(\mathrm{P}=0,6144)$, contudo influenciou a concentração do $\mathrm{CPK}(\mathrm{P}=0,0261)$. Suínos que foram transportados nos boxes da frente apresentaram menores valores de CPK em relação aos suínos transportados nos boxes do meio e atrás. Este efeito, possivelmente, tenha sido gerado em função de suspensão dianteira do caminhão. $\mathrm{O}$ modelo de carroceria utilizado era caracterizado por ser um $6 \times 4$ (seis pontos de apoio no solo, e quatro pontos de tração) assim, a suspensão traseira é mais dura, o que pode ter contribuído para o incremento dos valores do CPK dos suínos transportados nos boxes do meio e atrás

O piso (inferior e superior) e o lado (direito e esquerdo) da carroceria do caminhão não influenciaram as concentrações de glicose $(\mathrm{P}=0,2600 \mathrm{e} \mathrm{P}=0,6912), \mathrm{CPK}$ $(\mathrm{P}=0,3868$ e $\mathrm{P}=0,4410)$ e lactato $(\mathrm{P}=0,9499$ e $\mathrm{P}=0,7409)$, respectivamente.

Não foi observado efeito $(\mathrm{P}=0,7388)$ do período de descanso dos suínos, no frigorífico, sobre a concentração do cortisol da saliva (Figura 1). Os resultados obtidos, no presente estudo, diferem dos obtidos por WARRISS et al. $(1992 ; 1998)$ que verificaram redução significativa na concentração do cortisol do sangue dos suínos, quando esses permaneceram por maiores PDF. A concentração de cortisol na saliva, ao contrário da variação da concentração do cortisol no sangue, é um parâmetro que tem uma variação lenta para refletir as respostas fisiológicas diante do estresse ou ausência deste em períodos de curta duração. Assim considerado, o intervalo ou tempo máximo (6 horas) entre as coletas de saliva, nos suínos submetidos ao tratamento com menor e com maior tempo de descanso, não foi suficiente para induzir uma redução na concentração de cortisol na saliva, embora a diferença entre os extremos, na média, tenha sido $25 \%$ inferior para o maior tempo de descanso. Considerando a forma de variação da concentração de cortisol na saliva, ainda não está conhecido plenamente se, na presença de um evento estressante (transporte, por exemplo), a velocidade de aumento na concentração tem a mesma natureza ou comportamento do que a redução da sua concentração na ausência de um evento estressante (descanso nas baias no frigorífico). Via de regra, é considerado que a concentração de cortisol na saliva pode representar melhor os fenômenos ou eventos de longa duração, enquanto que a concentração do cortisol no sangue pode representar melhor os eventos estressantes de curta duração (BUSHONG et al., 2000; SCHÖNREITER et al., 1999).

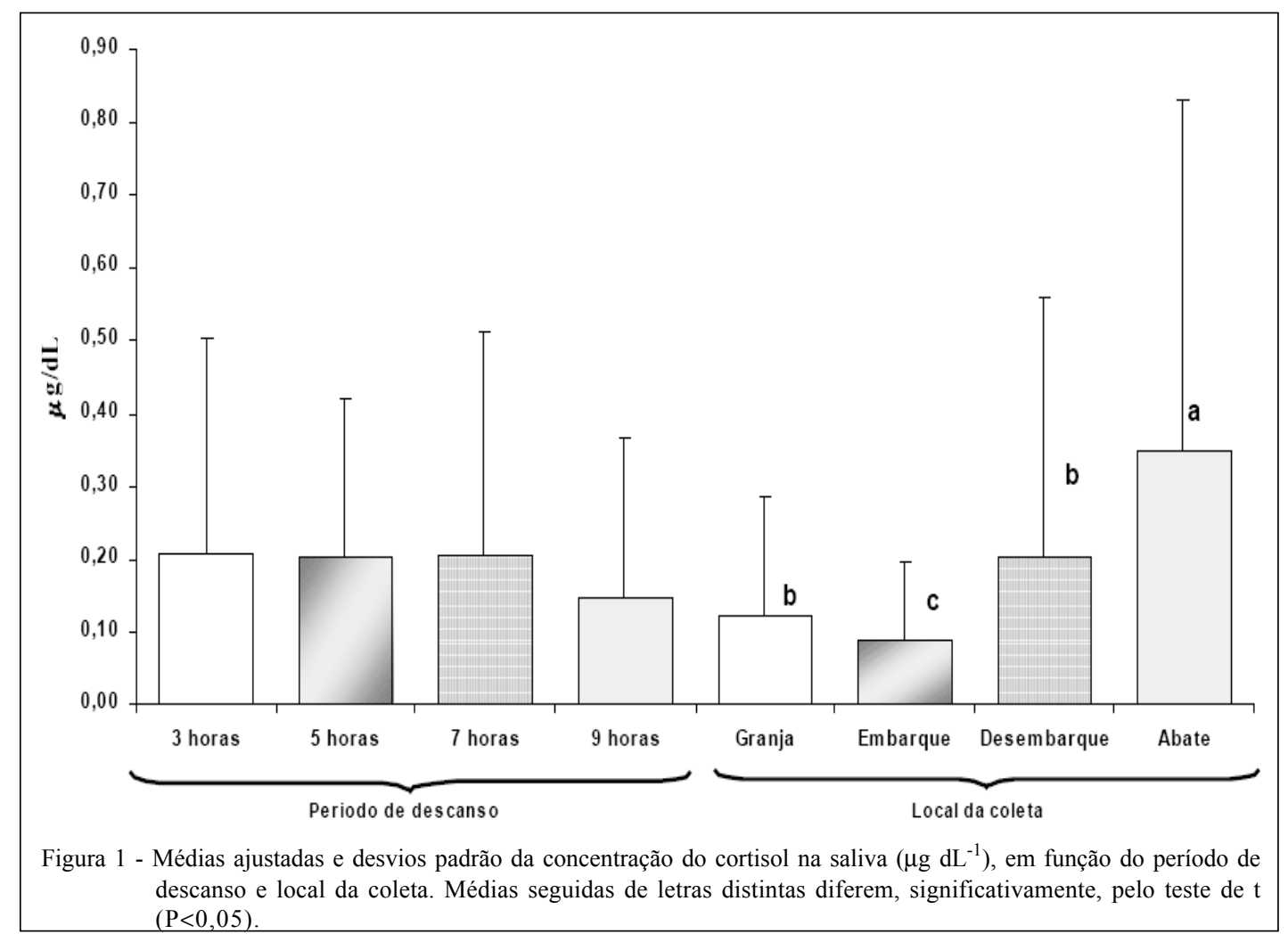

Ciência Rural, v.39, n.3, mai-jun, 2009. 
Por outro lado, o local da coleta influenciou $(\mathrm{P}=0,0001)$ a concentração do cortisol da saliva dos suínos, demostrando que o manejo pré-abate promoveu um incremento em sua concentração. Nas 24 horas anteriores ao início do manejo pré-abate, na granja, a concentração do cortisol era de $0,112 \mu \mathrm{g} \mathrm{dL} \mathrm{dL}^{-1} \mathrm{e}, \operatorname{logo}$ após o embarque, os valores médios do cortisol eram de $0,088 \mu \mathrm{g} \mathrm{dL}^{-1}$. Imediatamente após o desembarque dos animais no frigorífico, valores superiores $\left(0,205 \mu \mathrm{g} \mathrm{dL}^{-1}\right)$ foram detectados. Antes do abate, porém, na média, foram detectadas as maiores concentrações $(0,347 \mu \mathrm{g} \mathrm{dL}$ ${ }^{1}$ ) de cortisol na saliva dos suínos (Figura 1). Esses resultados, representando um intervalo de tempo maior (24 horas antes do início do manejo pré-abate, 2 horas para carregamento, transporte e instalação dos animais nas baias de descanso e o tempo de descanso) e intensidades de estresse diferenciadas conseguiram demonstrar, de forma nítida, o efeito do manejo pré-abate sobre as concentrações do cortisol na saliva.

Estudos realizados por GEVERINK et al. (1998a; 1998b; 1998c) também verificaram aumento significativo na concentração do cortisol da saliva dos suínos durante o transporte desses. PÉREZ et al. (2002b) observaram que suínos que foram transportados por 15 min e abatidos após o transporte apresentaram maiores valores de cortisol no sangue em relação aos animais que foram transportados por 3 horas.

Observou-se efeito $(\mathrm{P}=0,0420)$ da interação período de descanso e local da avaliação ( 24 horas antes do manejo pré-abate, antes do embarque dos suínos na granja, no transporte e no período de descanso no frigorífico) sobre a freqüência cardíaca dos suínos (Figura. 2). Independentemente do período de descanso dos suínos no frigorífico, no transporte, os suínos apresentaram os maiores valores da freqüência cardíaca em relação aos demais locais avaliados $(\mathrm{P}<0,05)$. Não foi observada diferença significativa entre os períodos de descanso em todos os locais de avaliação, o que já era esperado para freqüência cardíaca na granja, no embarque e no transporte, uma vez que os animais ainda não tinham sido submetidos ao período de descanso, quando da realização dessas medições. Os resultados obtidos, no presente estudo, validaram aqueles encontrados por GEERS et al. (1994), que também observaram aumento significativo na freqüência cardíaca dos suínos após o seu transporte. VILLÉ et al. (1993) também verificaram que, durante o transporte, os animais apresentaram aumento em sua freqüência cardíaca, já GEVERINK et al. (1998b) observaram um incremento (picos) da freqüência cardíaca dos suínos no embarque e desembarque.

No presente trabalho, os valores médios da freqüência cardíaca durante o manejo pré-abate estão dentro dos padrões fisiológicos de suínos, para o grupo genético e peso corporal estudados.

\section{CONCLUSÕES}

O manejo pré-abate condicionou um incremento na concentração do cortisol da saliva com aumentos contínuos desde o embarque até o abate. A freqüência cardíaca dos suínos, no período de

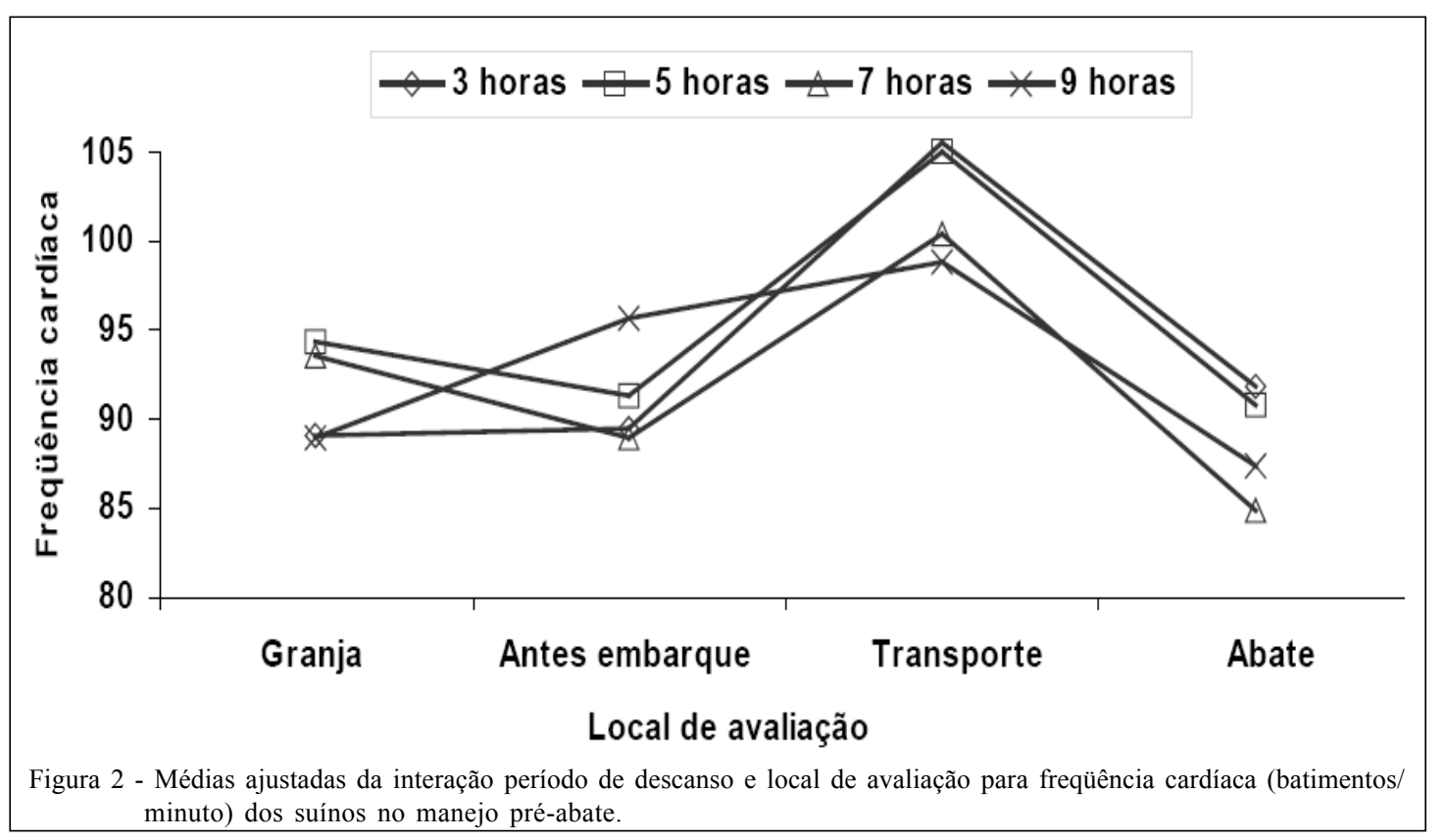

Ciência Rural, v.39, n.3, mai-jun, 2009. 
descanso no abatedouro, foi reestabelecida a valores normais. Níveis de creatina fosfoquinase, determinados no plasma dos suínos no abate, sofrem influência da posição dos animais dentro da carroceria em função das características do caminhão. O período de descanso dos suínos, no frigorífico, influenciou a concentração de lactato do sangue dos suínos no momento do abate. Os valores de lactato, após o período de três horas de descanso no abatedouro, estão relacionados ao ritmo de atividade dos animais e ao nível de atividade no frigorífico. Essas conclusões são pertinentes para as duas estações do ano em que o experimento foi realizado.

\section{REFERÊNCIAS}

BARTON-GADE, P.A. et al. Effect of tier ventilation during transport on blood parameters and meat quality in slaughter pigs. In: EU-SEMINAR: NEW INFORMATION ON WELFARE AND MEAT QUALITY OF PIGS AS RELATED TO HANDLING, TRANSPORT AND LAIRAGE CONDITIONS, 1996, Mariensee. Proceedings... Landbauforschung Völkenrode, 1996. V.166, p.101-116.

BERTOLONI, W.; SILVEIRA, E.T.F. The influence of genetic background and stunning systems on welfare and meat quality of brazilian swine. In: INTERNATIONAL CONGRESS OF MEAT SCIENCE AND TECHNOLOGY, 49., BRAZILIAN CONGRESS OF MEAT SCIENCE AND TECHNOLOGY, 2., 2003, Campinas, SP, Brasil. Anais... São Paulo: Institto de tecnologia de Alimentos, 2003. p.365-366.

BUSHONG, D.M, et al. Salivary and plasma cortisol response to adrenocorticotropin administration in pigs. Laboratory Animals, London, v.34, p.171-181, 2000.

DALLA COSTA, O.A. Effects of the season on the year, truck type and locations on truck on skin bruises and meat quality in pigs. Livestock Science, Amsterdam, v.107, p.29-36, 2005.

GEERS, R. et al. Transport of pigs different with respect to the Halothane Gene: stress assessment. Journal of Animal Science, Champaign, v.72, p.2552-2558, 1994.

GEESINK, G.H. et al. Short-term feeding strategies and pork quality. Meat Science, Kidlington, v.67, p.1-6, 2004.

GEVERINK, N.A. et al. Effects of regular moving and handling on the behavioral and physiological responses of pigs to preslaughter treatment and consequences for subsequent meat quality. Journal of Animal Science, Champaign, v.76, p.2080-2085, 1998a.

GEVERINK, N.A. et al. Responses of slaughter pigs to transport and lairage sounds. Physiology \& Behaviour, v.63, p.667673,1998 b.
GEVERINK, N.A. et al. Effects of simulated lairage conditions on the physiology and behaviour of pigs. Veterinary Record, London v.29, p.241-244, 1998 c.

HALL, S.J.G. et al. Welfare aspects of the transport by road of sheep and pigs. Journal of AppliedAnimal Welfare Science, New York, v.1, p.235-254, 1998.

HAMBRECHT, E. et al. Negative effects of stress immediately before slaughter on pork quality are aggravated by suboptimal transport and lairage conditions. Journal of Animal Science, Champaign, v.83, p.440-448, 2005.

LEBRET, B. et al. Influence of rearing conditions on performance, behavioral, and physiolgical responses of pigs to preslaughter handling, carcass traits, and meat quality. Journal of Animal Science, Champaign, v.84, p.2436-2447, 2006.

LUDTKE, C.B. Influência do estresse no manejo préabate na qualidade da carne suína. 2004. 53f. Dissertação (Mestrado em Ciência e Tecnologia Agroindustrial) Universidade Federal de Pelotas, Pelotas, RS.

PÉREZ, M.P. et al. Influence of lairage time on some welfare and meat quality parameters in pigs. Veterinary Record, London, v.33, p.239-250, 2002a.

PÉREZ, M.P. et al. Effect of transport time on welfare and meat quality parameters in pigs. Meat Science, Kidlington, v.61, p.425-433, 2002b.

RANDALL, J.M. et al. Vibration on pig transporters: implications for reducing stress. In: EU-SEMINAR: NEW INFORMATION ON WELFARE AND MEAT QUALITY OF PIGS AS RELATED TO HANDLING, TRANSPORT AND LAIRAGE CONDITIONS, 1996, Mariensee. Proceedings... Mariensee, Germany: Landbauforschung Völkenrode, 1996. p.143-159.

SAS INSTITUTE INC. *System for Microsoft Windows:* release 9.1.3, 2002-2003. 1 CD-ROM. Address: SAS INSTITUTE INC.100 SAS Campus Drive Cary, NC 275132414, USA.

SCHÖNREITER, S. et al. Salivary cortisol as a stress parameter in piglets. Tierärztliche Praxis Ausgabe G. Grosstiere/ Nutztiere, Berlin, v.27, p.175-179, 1999.

VAN DER WAL, P.G. et al. The effect of stress, applied immediately before stunning, on pork quality. Meat Science, Kidlington, v.53, p.101-106, 1999.

VILLÉ, H. et al. Electrocardiogram parameters of piglets during housing, handling and transport. Animal Production, Edindurg v.56 p.211-216, 1993.

WARRISS, P.D. et al. Time in lairage needed by pigs to recover from the stress of transport. Veterinary Record, London v.29, p.194-196, 1992.

WARRISS, P.D. et al. Effect of lairage time on levels of stress and meat quality in pigs. Animal Science, Ottawa, v.66, p.255 261, 1998. 